\title{
A DISCUSSION OF THE REPORT OF THE COMMITTEE ON GEOMETRY.
}

\author{
By G. C. Shutts, * \\ Whitewater, Wis.
}

After studying the report, one feels that it must meet with general approval among teachers in nearly every particular. The statement that it is "meant to be evolutionary not revolutionary" suggests the temper of the movement. It appeals to the good sense of teachers and asks them to co-operate in the suggested improvements as far as their judgments endorse any changes. While a few criticisms appeal to one as he reads, they are upon minor points and serve to emphasize rather than otherwise the value of the report.

It is suggested that certain terms be left undefined. Few teachers will dissent in regard to such words as Whole, Part, Between, In, Through, Divide, and this class of words not usually held to be technical terms of geometry; but there will be more or less difference of opinion upon the words Point, Line, Surface, Plane, and Straight, named by the committee. Therc may not be agreement in the language of the definitions. Many may even think they can not be satisfactorily defined, but most will agree, and this I take to be the position of the committee, that a careful discussion of their properties and limitations is necessary to clear of error the crude notions of pupils, and to serve as a basis of authority for future work. (It may be wisdom, for this association at some future time after mature deliberation, to formulate definitions or at least a statement of limitations in form of a discussion of above terms as well as of a few others. I would suggest that Angle be added to the list.)

There is no doubt that there is positive need of a set of words which shall respectively express the different meanings of the term Equal. Equal and Equivalent do fairly well; equal, for equal in all respects, and equal in magnitude have been used with reasonable accuracy. "Congruent" suggested by the committee for the equality of identity, is an awkward word and so foreign to the language of every day life that I doubt its expediency. If used by teachers and text, it may be forced upon the pupil while

\footnotetext{
* Read before the Mathematics Section of the Central Association of Science and Mathematics Teachers, St. Louis, Mo., Nov. 30, 1907. Printed copies of the Geometry Report can be obtained from the Secretary of the Section, Miss Mabel Sykes, by enciosing a stamp to lier at 438 F. 57 th St. Chicago, I11, The paragraphs refer to the respective paragraphs in the report.
} 
in recitation, and possibly in conversation during the study of the lessons, but will soon pass out of use and equal will take its place.

The use of Line, Sect, and Ray for the different notions that have centered in the word Line, can not be too strongly emphasized. The word Line has been made to do triple duty long enough. But I confess I can not see why, for mathematics involving the area of the circle, Circumference should be discarded and "Circle" be made to do double duty. Is it not taking a step backwards and towards a confusion of ideas?

I believe the abolition of the term axiom will meet with gerleral approval, and assumption can well take its place. There is wisdom, too, in delaying the statement of an assumption until it is needed. Its force will then appeal to the judgment of the pupil and he will be more likely to remember it and seek its aid when again it is needed, In studying the list of assumptions suggested by the committee, one is reminded frequently of the Hilbert axioms, and looks vainly for many of the axioms of Euclid. Many of the new assumptions will be welcomed, but why discard the time honored "Equals subtracted from equals", "Equals multiplied by the same or equals", etc.? Many writers on geometry and teachers have been unconsciously assuming certain truths that should have been stated, and the list cited by the committee calls attention to many of them. But I doubt, however, if the average boy could be made to think it anything but a waste of time to refer to numbers 4 and 5. If No. 7 is accepted, and the meaning of angle and straight angle is undestood, No. 9 follows as a consequence and need not be assumed. No. 8 is easily demonstrated, if No. 9 and the method of superposition is granted. Again granting the need of No. II, No. I4 should be proved by it and not assumed. When it has been established that two circles can be made to coincide if their radii are equal, and that the magnitude of an angle determines the position of one side when the position of the vertex and the other side is known, why is it any more difficult to establish No. I6, viz., that "central angles inter cept equal arcs," than to prove that "two triangles are equal when two sides and the included angles are respectively equal?" If proof by superposition be denied, the problem may indeed be a difficult one.

Terms that depend upon the demonstration of a given theorem should follow that theorem, as Distance, Center of a Regular Polygon, Apothem, Polar Distance, etc. But there are advantages 
in studying all of a group of related definitions, "em bloc," in that it gives the student a classified notion of a given subject. For instance I would prefer the triangle definitions together; the quadrilateral definitions together, etc. If scattered about as they need to be used, they may, by the order in which they occur be thrown out of their relation of dependence upon one another, viz., the relation of genus and species, and in any case, the pupil will have more difficulty in building up the subject in his mind in its true classification. The meaning of definition, viz., the name of the proximate genus of the concept with a statement of the difference between the species of the genus, will be harder to appreciate; in fact, he may wholly miss the distinction of genus and species if not presented together in a classification.

The use of figures is sadly abused. The report wisely calls attention to the matter. What teacher does not find his class as a whole making all their figures a copy of those in the book? The pupil depends upon the figures in the text and fails to see that he gains the truth from the figures rather than from the theorem. If he can be induced to study the theorem with the figuies covered and construct from it his figure, finally using the one in the text as a check, the tendency decried by the committee will be largely remedied. The figures will not be exactly like those in the book studied, and this very fact if encouraged will engender a pride in independent work. Many texts do not define Corresponding Angles, Alternate Interior Angles, etc., but simply make a drawing and refer to the angles in the various positions. by name. In such cases, it is true one must depend upon pictorial evidence to determine which are alternate interior angles formed by the opposite sides of a parallelogram and the diagonal. If a genuine definition has been given, this definition becomes legitimate authority. It is true "that a demonstration should aim to recognize and acknowledge all the sources upon which it depends ;" but it is true, too, that in the beginning, if this is done, the pupil will be lost in the maze of technicalities. If the main authorities are given, he can appreciate the argument, and no violence is done in his mind to the rigor of the denionstration. As he grows in strength more and more, he can be made to appreciate all the sources of dependence which should be credited.

One of the most common fallacies of students in original work is the tendency to redundancies lamented by the committee. To illustrate; We have all heard again and again, "Bisect the ver- 
tical angle of an isosceles triangle and extend to the middle of the base". or "draw it perpendicular to the base," "Draw a perpendicular from the vertex of an isosceles triangle to the base at its middle point." "Draw a radius perpendicular to a chord at its middle point," etc.

That part of the report which appeals to me most strongly is the challenge of the treatment so common in texts of proportion. For, to prove the truths in the theory of proportion algebraically and then apply them to geometric magnitudes without noting the necessary limitations, is, in the words of the committee, "extremely unfortunate." The distinction between Number and, Quantity should be emphasized and both clearly considered in the theory of proportion with the consequent limitations in use of Quantity noted. For instance, a proportion of quantities can not be taken by alternation unless the units of the terms of both ratios are the same, because the definition of ratio would be violated. If Ratio is to be defined algebraically then Quantity must be measured, which at once demands a full appreciation of tunit and number or coefficient. If the algebraic definition of product is to be used, such expressions as $A B$ need interpretation. The pupil should not use it regardless of meaning; $i$, e., whether $A$ and $B$ are both numbers, or one number and one quantity; or as sometimes happens in both text and school room, both seem to be quantities. The using of symbols with no appreciation of their meaning is, to say the least, a waste of time. It would assist the student of geometry if in his algebra and arithmetic, the function of coefficient and unit could be more fully developed: In the case of two factors, as $3 \times$ (times) 5 , he should know that the multiplier is the number or coefficient and the multiplicand the unit; that if both were numbers, either may be taken for the unit, according to convenience. In the case of addition of, say, $3 \times 5$ and $3 \times 7$, the pupil should appreciate that the unit should be selected for brevity in adding; as 7 threes and 5 threes; or in multiplication, of say, $6 \times 3 \times 5$, it is a matter of convenience whether to say $6 \times 3$ fives or $6 \times 5$ threes. Could the pupils be trained to a fuller appreciation of the number unit, the quantity unit, and their relation to coefficients, the addition of products in geometry would not seem so foreign to them; as in finding the area of a regular polygon in $1 / 2 \mathrm{~B}$ (base) $\times A$ (alt.) $+5 / 2 \mathrm{~B} \times \mathrm{A}$, etc. If $\mathrm{A}$ and $\mathrm{B}$ have been taken as measures of lines. viz.. numbers, he would see at once that the unit and coef- 
ficient may be selected on the basis of what is demanded of the sum. In short, in his thinking, the pupil should be governed, as is any other workman, by the nature of his materials and what he wishres to make of them.

It is in the nature of the subject that each statement made in a demonstration should be based upon authority. But there should be a reason apparent if that authority is purely arbitrary. I doubt whether it is wise to assume a proposition that can be demonstrated, unless that demonstration is too difficult at the time for the pupil; for instance, the theorem of central angles and their arcs before referred to and other assumptions.

It is probably wise with some classes, or some pupils in a class, to assume those comparisons of ratios involving incommensurable numbers in the first course if two courses are scheduled, or entirely if the course is but a year. It is probably best in any case to assume, but clearly assume, those theorems concerning the multiplication and division of variables by constants, etc. To use these and other theorems in the process of demonstration without distinctly recognizing them as authority, has much to do with the confusion in the pupil's mind in regard to what constitutes a demonstration and his consequent loss of confidence in his power to reason. At one time, he is held sharply to account for authority that to his mind is puerile, and again he is taught to make statements that he can not understand, giving no authority. Is it any wonder that he is lost in the maze of it and resorts to any subterfuge to make his rank so as to be rid of the subject? The proposition: "Two variables are equal if their limits are equal," may well be assumed.

The position of the committee that "the more careful study of a much smaller number of propositions would achieve the same, if not better results" is, I believe, a too modest statement of the fact. I believe it would be nearer the whole truth to have said "would achieve far better results." It is to be deplored that the teachers feel constrained to drive every class and every pupil in the class over the same course. In consequence, they are impatient of the time required by pupils to really think out the new truths. The appreciation of a new concept is a slow process. The teacher's memory of the argument brings the result quickly and, judging too often from his own standpoint rather than the pupil's, he fails to give him sufficient time for real thinking. The pupil gets the mistaken notion that his slowness is more or less a 
disgrace; hence, seeks other and questionable means to meet the requirements-the requirements too often simply a glib rehearsal of the language of the book. Less matter worked out to a full understanding, - the more independently the better, on the other hand, will give that confidence and pleasure that always accompanies mastery of a subject. Because each class is composed of pupils of varying ability, an elastic course is desirable. This can be accomplished by putting as the necessary course of theorems the minimum that will furnish sufficient matter to meet the usual college requirements. The other theorms dispersed through the work as exercises will give free play for the swiftest student, and each can get the fullest development possible. A rigid course perhaps suited to the medium holds back and disgusts the brilliant student, while it is absolutely discouraging to the slowest. The exercises again had better be distributed throughout the work from day to day, letting each lesson be a study of both necessary theorems and exercises, rather than the study of a chapter of theorems, followed by several pages of exercises. Hence, I believe the committee has done wisely in laying out a "tentative list" of necessary theorems, to guide the teacher who may not have the time or confidence to make such a course by elimination for himself. It is to be lamented that so many texts seem to be a cyclopedia of geometric truths, rather than a text to guide the teacher in his function as an instructor. Probably no two people without a conference would agree upon a particular list, probably no one would from year to year agree with himself upon a definite list. But such a list as the conmittee proposes will be suggestive and give courage to many to modify the course to suit the needs of their classes.

Finally, I would say, to emphasize, if I can, the position of the committee, that the closer one can keep to the experience of the student in high school geometry, the more value will accrue. To keep the student interested, he must see it a condition actually in his environment. When a notion is fully in mind, to let the pupil make application of it in physics, mensuraton, etc., is true pedagogy. The pupil must image each notion at the first, or his time is wasted; when once imaged, the symbol may safely stand for the notion, if well guarded. Hence, if necessary, the notion must be gotten from some physical representation. But it should be remembered that it is better to have the notion built up in his mind purely from the statement of it than from the geometric 
figure, or physical representation. To spend one's time in building forms with tooth picks, wires, etc., or making shaded pictures and studying them, is a waste of time except for the slow pupil who at first needs this simple device to image the required notion. Such, might be termed kindergarten thinking. A higher kind, symbolic thinking, should take its place as soon as the mind is ready for it. The rare mind which can organize its facts, making new combinations, new constructions, perhaps developing new theories, has reached a still higher development. Geometry with an elastic course rationally administered furnishes opportunity for development for each kind of mind that seeks its assistance.

There is no doubt that if this report, revised, elaborated, illustrated and endorsed by this body, can be put into the hands of every teacher of geometry within the bounds of this association, such an improvement can be inaugurated in the teaching of the subject that its usefulness in the curricula of our secondary schools shall be fully equal to the claims of its most ardent friends. I wish to endorse the work of the committee and trust that the results may be utilized to the fullest extent possible

\section{DISCUSSION OF THE REPORT OF THE COMMITTEE ON ALGEBRA. ${ }^{ \pm}$}

By Florian Cajori, Colorado College, Colorado Springs.

It is a pleasure to discuss a report with which one is in substantial agreement. The main features of the report are a diminution of the amount of formal algebra during the first year course of the high school, an increase in the amount of problem work for that year, emphasis, throughout the high school period, upon the correlation of algebra and arithmetic, algebra and geometry, algebra and physics. If judiciously and skillfully carried out, these recommendations ought to lead to improvements in our teaching. A boy once decided to keep chickens, and to supply the family witli fresh eggs. But the bantam chickens which he bought laid eggs that were miserably small. So the boy finally resorted to the expedient of hanging up in the chicken coop a big ostrich egg, with the notice. "Keep your eye on this and do your best." We teachers should keep our eye on this report and do our best.

\footnotetext{
1 Read before the Mathematics Section of the Central Association of Science and Matr ematics Teachers, St. Louis, Mo., November 29, 1907.
} 